\title{
The multi-risk vulnerability of global coal regions in the context of mine closure
}

\author{
K Svobodova The University of Queensland, Australia \\ JR Owen The University of Queensland, Australia \\ E Lebre The University of Queensland, Australia \\ M Edraki The University of Queensland, Australia \\ A Littleboy The University of Queensland, Australia
}

\begin{abstract}
Coal mining industries face real challenges to meet legal demands on a low carbon future. The history of coal in industrial transitions seems to come to a rapid end, accompanied by widespread boom of closing active coal mining projects. This change can result in negative ramifications for coal mining regions, involving a complex interplay of multiple risks. In this paper, we aim to analyse the complexity of environmental, social, and governance factors that can cause significant difficulties in closure of coal mining operations. We identify multi-factor risk profiles for operating mines by applying spatially explicit indicators within a proposed multi-risk framework. The indicators have not been captured by conventional market, as they tend to be more long-term oriented in the context of strategy and performance. We map eight risk categories: stability, water and climate, biodiversity, vulnerability of land uses, indigenous people, social fragility, political fragility, and regulatory environment, and analyse their effect on a global dataset of active open pit coal mines. The spatial analysis reveals that a significant proportion of the projects face accumulation of multiple risk factors. A total of 552 projects out of 916 show medium to very high-risk occurrence. In this paper, we present global risk vulnerability across the coal mining projects by indicating extent to which operators of the mines face multiple risk factors when planning for closure.
\end{abstract}

Keywords: coal phase-out, ESG, multi-factor risk, rehabilitation

\section{Introduction}

Coal industries have been challenged by a movement targeting a reduction in global emissions. Over one hundred major financial institutions have issued restrictions on investments in coal (Buckley 2019). The European Parliament has called for the European Union to exit coal by 2030 (European Environmental Bureau 2019). This year, for the first time in history, an Australian judge ruled against a new coal mine development citing community concerns about climate change (McGowan \& Cox 2019). These and other actions forecast changes in the coal mining industry with ramifications for the energy sector worldwide. In some jurisdictions, a rapid and widespread closure of coal mining projects is expected in order to meet legal demands on a low carbon future. All this can result in negative consequences for coal mining regions, involving a broad range of complex risks. To achieve long-term sustainability and social gain in these regions, closure approaches should consider co-occurrence of multiple risks.

Coal mining has specific characteristics that warrant particular attention (Salmon 2018). When open pit coal mines operate, millions of tons of rock need to be moved, resulting in distinct landscape changes. Key features of this change are spoil piles, rejects and tailings depositories, and final voids where mining occurred immediately prior to closure. These human-made environments, and their interplay, are more sensitive to various factors and their interplay than natural ecosystems. They can create a complex set of long-term environmental and social issues and challenges for post-mining land use and rehabilitation as previously shown by, for example, Lechner et al. (2017). Therefore, a broad range of environmental considerations are 
present in investor decision-making in mine closure planning. In the open pit, large-scale coal mining, environmental risks primarily include stability of waste storage facilities and final voids, and water and biodiversity impacts (Hendrychová \& Kabrna 2016; Walters 2016). The social risks of coal mining refer to the nature of multi-faceted relationships between the company, the local community, and host society (Bainton \& Holcombe 2018), to the vulnerability of the environment caused by cumulative human disturbances (Venter et al. 2016), and to the dynamics associated with cultural heritage, and indigenous and tribal lands (O'Faircheallaigh 2017). The governance risks highlight the link between institutional frameworks and the achievement of Sustainable Development Goals (United Nations Development Programme 2015). These risks include the legal and regulatory systems, processes and mechanisms that control corporate decisions and actions, corporate disclosure and transparency, corruption, taxation regime, trade barriers, and other political factors (Organisation for Economic Co-operation and Development 2017).

In this paper, we use the framework of environmental, social, and governance (ESG) risks in global mining industry environment as previously developed by Valenta et al. (2019). Recent research about large-scale mining has highlighted the complexity of factors that need to be considered by companies, communities, and governments in designing, developing, operating, and closing large-scale extractive projects (Ranängen \& Lindman 2017). Addressing ESG issues has therefore become a critical part of business strategy. The ESG framework presented in this paper explores important risk domains that have not been captured by conventional market indicators. These risk domains tend to be long-term oriented in the context of strategy and performance.

The aim of the study is to analyse the complexity of ESG factors that can cause significant difficulties in closure of coal mining operations. Using the ESG framework presented in Section 2.1, we applied spatially explicit indicators to map multi-factor risk profiles of active coal mine projects on a global scale.

\section{Methods and data collection}

\subsection{ESG Framework}

In developing the ESG framework, we considered eight risk categories that can contribute to risk vulnerability of mining projects and entire regions, if being in high or medium importance: stability, water and climate, biodiversity (environmental risks); vulnerability of land uses, indigenous people, social fragility (social risks); political fragility, and regulatory environment (governance risks). The scheme of the framework is presented in Figure 1. Risk categories and risk factors (input datasets) are described in Appendix 1.

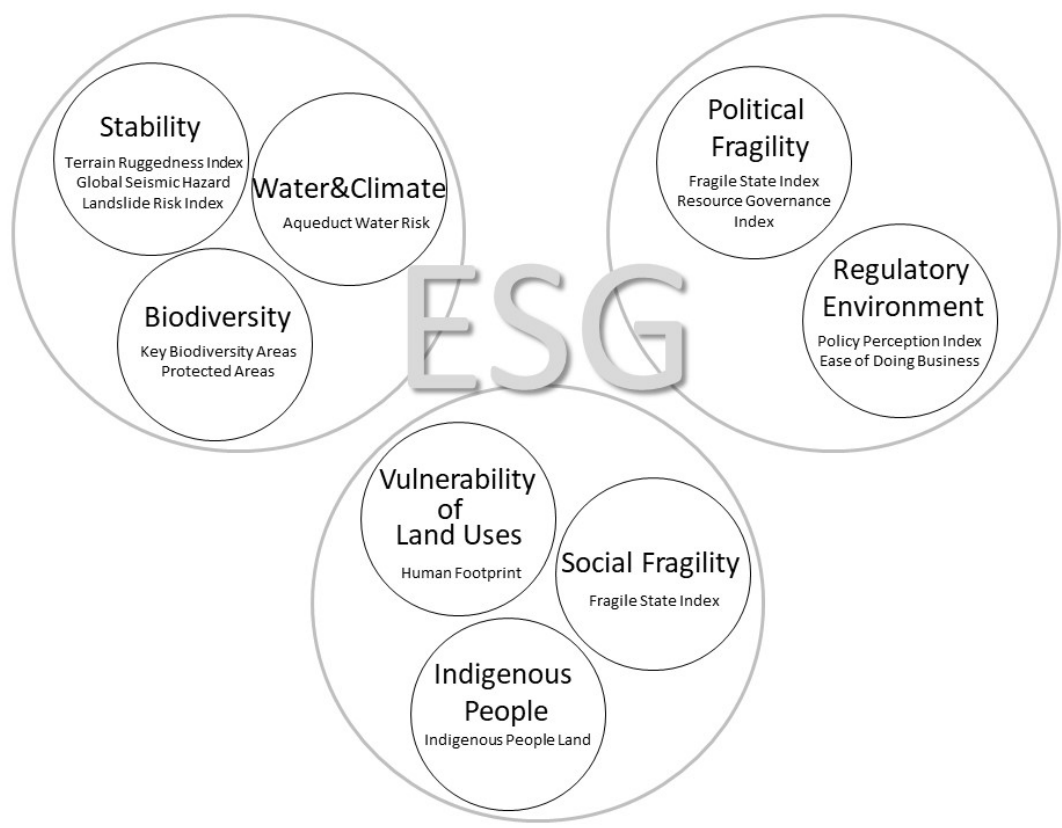

Figure 1 The ESG framework 
Every risk category compiles from various risk factors developed by previous research. The factors represent measures of particular risks or their aspects. Recognising diversity in completeness, content, and representativeness of the factors, different combinations of global risk factors were compiled for each risk category. Each of these factors, through their interactions with the mining project, are considered as having the potential to generate risks that can cause difficulties in mine closure planning.

\subsection{Data collection and spatial analyses}

The global dataset of active coal mines was extracted from the S\&P Global Market Intelligence database (S\&P Dataset) (S\&P 2019) as an Excel table with latitude and longitude coordinates and other characteristics such as projected closure year, mining method, activity stage, owner's name, and operator's name. The S\&P database is a commercial database where data are collected from publicly-released information provided by owners of mining properties. Although it is one of the largest, most comprehensive and up-to-date sources (Valenta et al. 2019), the data are limited by the extent of corporate self-reporting. For instance, artisanal and small-scale mining or some state-owned projects and other unreported mining activities are not covered by the database.

From the global dataset, we selected all projects where coal was a primary commodity and where an extractive method was open pit mining. To narrow the responsibility for the risk management toward the operating companies, we further reduced our sample to the mining projects that are active, under care and maintenance, on hold, or under litigation. As a result, we selected a set of 916 coal mining projects. Approximately $92 \%$ of these entries are projects in their active phase and the remaining $8 \%$ are under care and maintenance, on hold, or under litigation. Only 107 of the active projects (13\%) has reported a closure year (Figure 2).

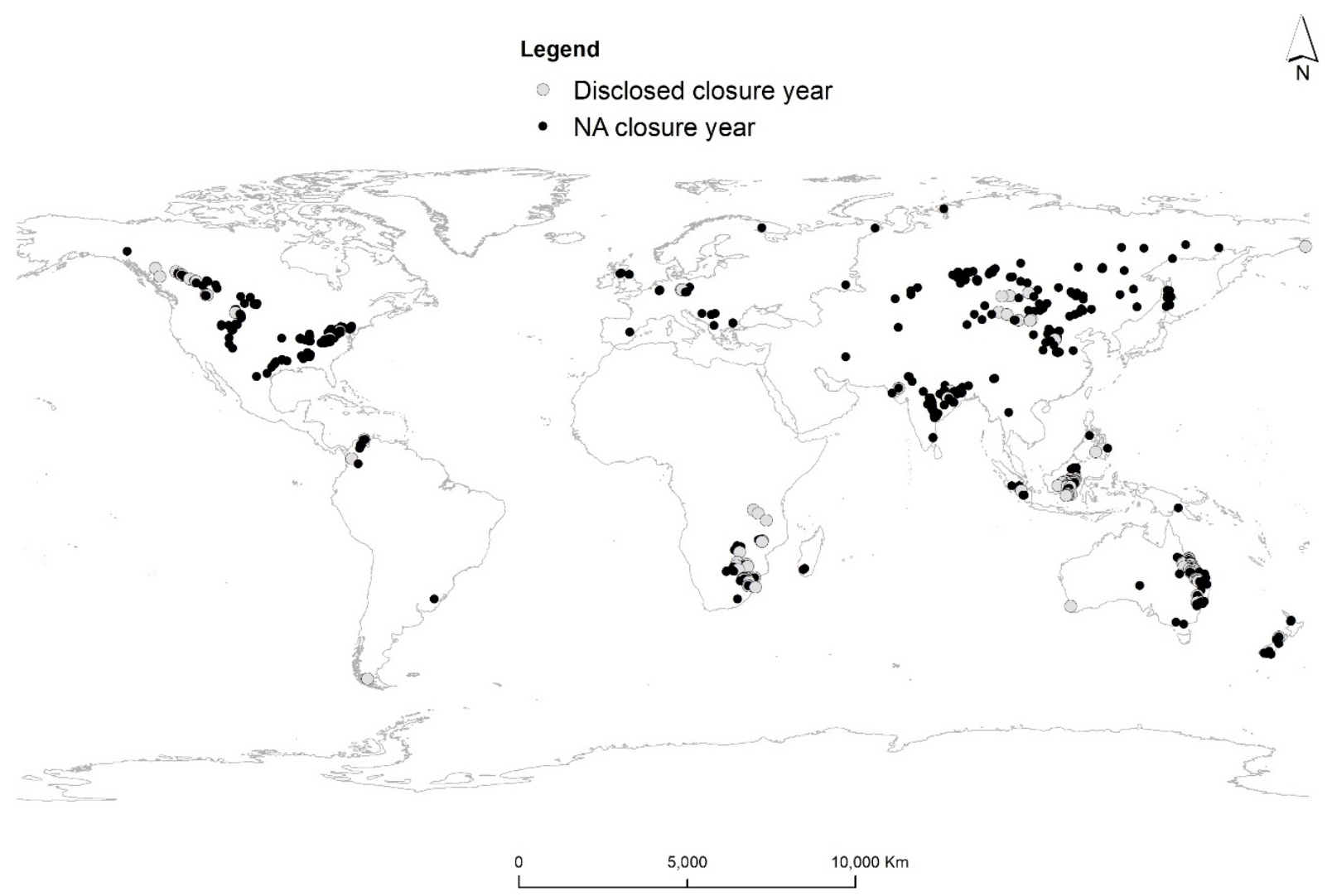

Figure 2 Coal mines selected for the study considering criteria such as active, open pit mining method, coal as a primary commodity. Only $13 \%$ of the projects have disclosed closure year

The input datasets for the ESG risk factors were downloaded from the sources listed in Appendix 1 as spatially referenced Geographic Information System data represented by rasters or vectors. 
All spatial analyses were conducted using ArcGIS 10.6 system software. The coordinates of coal mines were transferred to spatially explicit vector points. To identify multi-factor risk profiles of coal mine projects, we conducted overlay analyses Spatial Join (Analyses toolset) and Extract Multi-Values to Points (Spatial Analyst toolset) using the mines as a target layer and the ESG risk factors as join layers (Environmental Systems Research Institute 2018).

As a result of these analyses, every mining project received a level of risk for each ESG factor, based on risk calculation and normalisation presented in Table 1. For every mine, medium and high-risk factors were indicated as ' 1 ' and low level risks as ' 0 '. The ESG risk category was considered as severe when any of its input risk factors received a value of ' 1 '. For instance, the stability ESG risk category was recognised as severe when any from Global Seismic Hazard, Terrain Ruggedness Index, or Landslide Risk Index were showing high or medium risk (value ' 1 '). In the presented ESG framework, we considered all ESG risk categories as equivalent in terms of their impact on mine closure. Based on the risk profiles, all mines were divided into three categories:

1. Low-risk projects (zero to three ESG risks presented).

2. Medium-risk projects (four to six ESG risks).

3. High-risk projects (seven to eight ESG risks).

\section{Results}

A total of 102 mines (11\%) out of 916 projects were identified as high-risk projects, $450(50 \%)$ mines were assessed as medium-risk projects and the remaining 360 (39\%) projects as low-risk. The average number of risks was 4.2 per project (Figure 3).

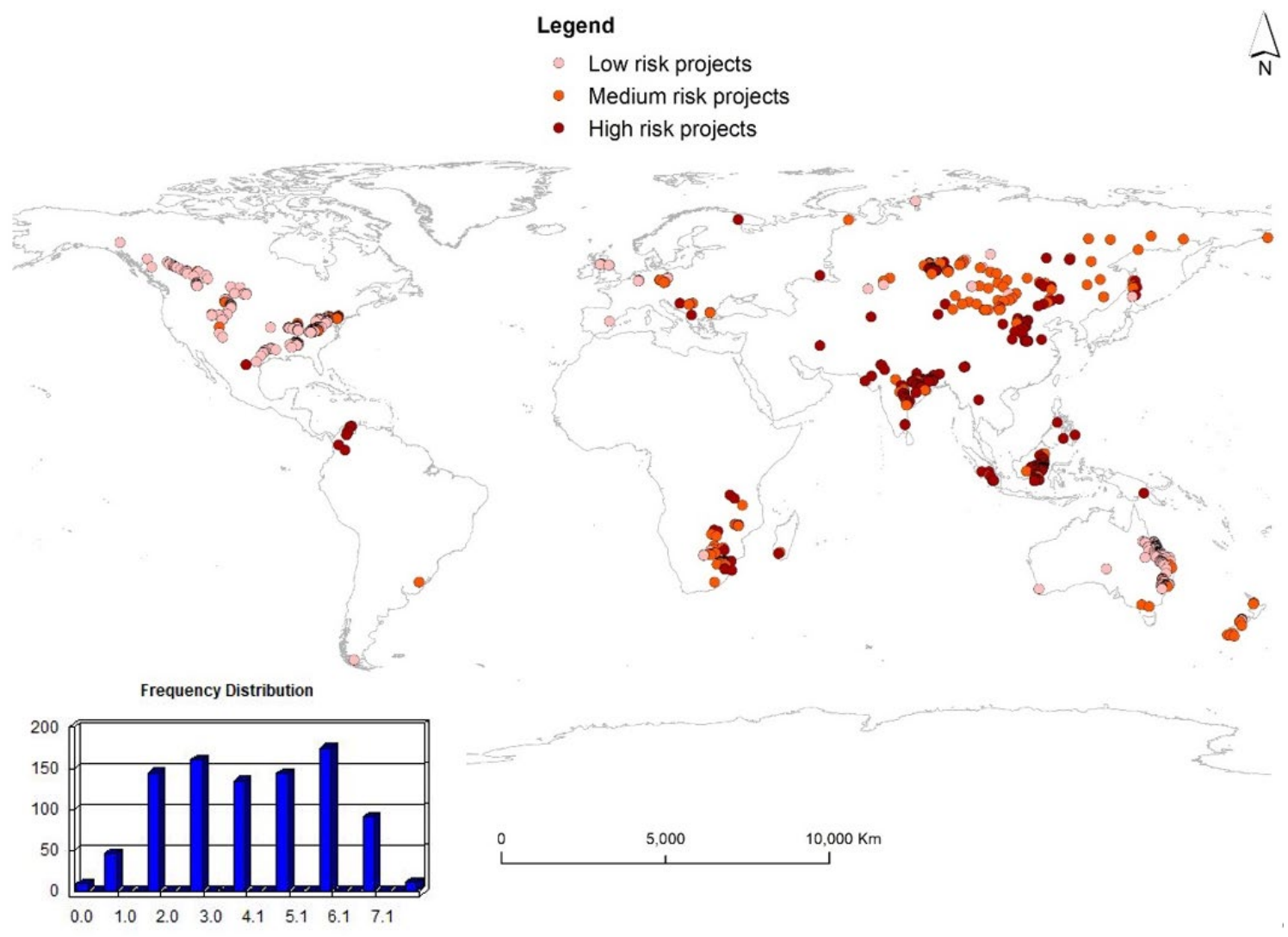

Figure 3 The global multi-factor risk profile of coal mining projects and the frequency distribution of multiple risks 
A total of 11 coal mine projects showed an occurrence of all eight ESG risks, which indicates an extremely high-risk profile (Figure 4). All these mines are presently active with an operations commencement date between 1968 and 2009. According to the S\&P Dataset, none of these projects have disclosed a closure year. Five of these projects are in India and run by four different companies. Five projects are in Indonesia operated by three various companies and one project is in Philippines.

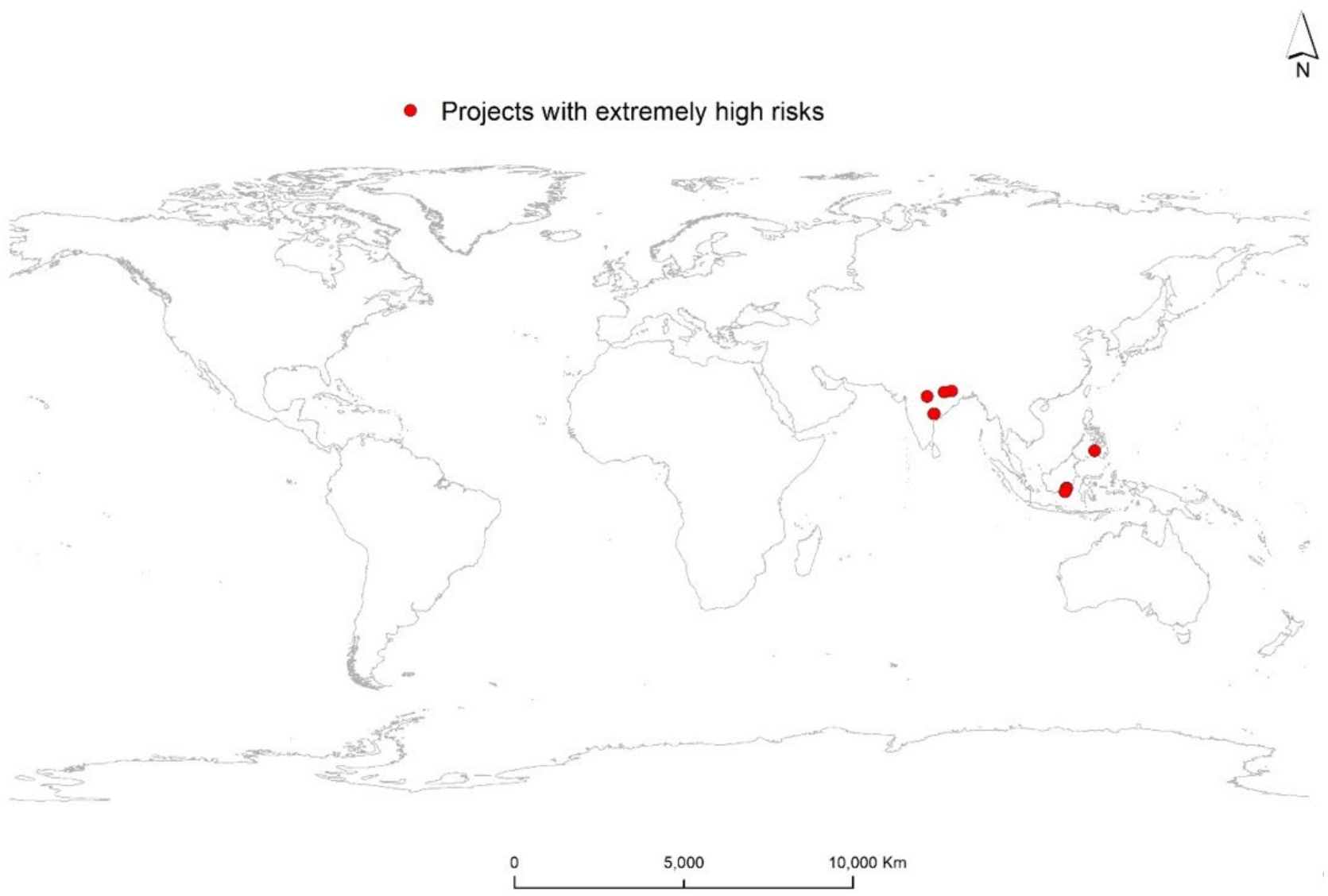

Figure 4 A set of 11 coal mining projects that show a complex co-occurrence of all risks across the ESG risk framework

The Adaro complex that includes the Wara, Tutupan and Paringin coal mines is one of the identified projects with extreme risk profile. They are located approximately $250 \mathrm{~km}$ north of Banjarmasin in South Kalimantan in Indonesia. The coal reserves amounting to 5.5 billion tonnes of coking coal are one of the largest coal reserves in the world. The annual production capacity of all three mines varies from 41 million tonnes (Tutupan) to 5 million tonnes (Wara) and 1 million (Paringin) tonnes of coal (Wood Mackenzie 2018). As shown in Figure 5, the project is in close proximity to the town Murung Pudak and surrounded by smaller villages. 


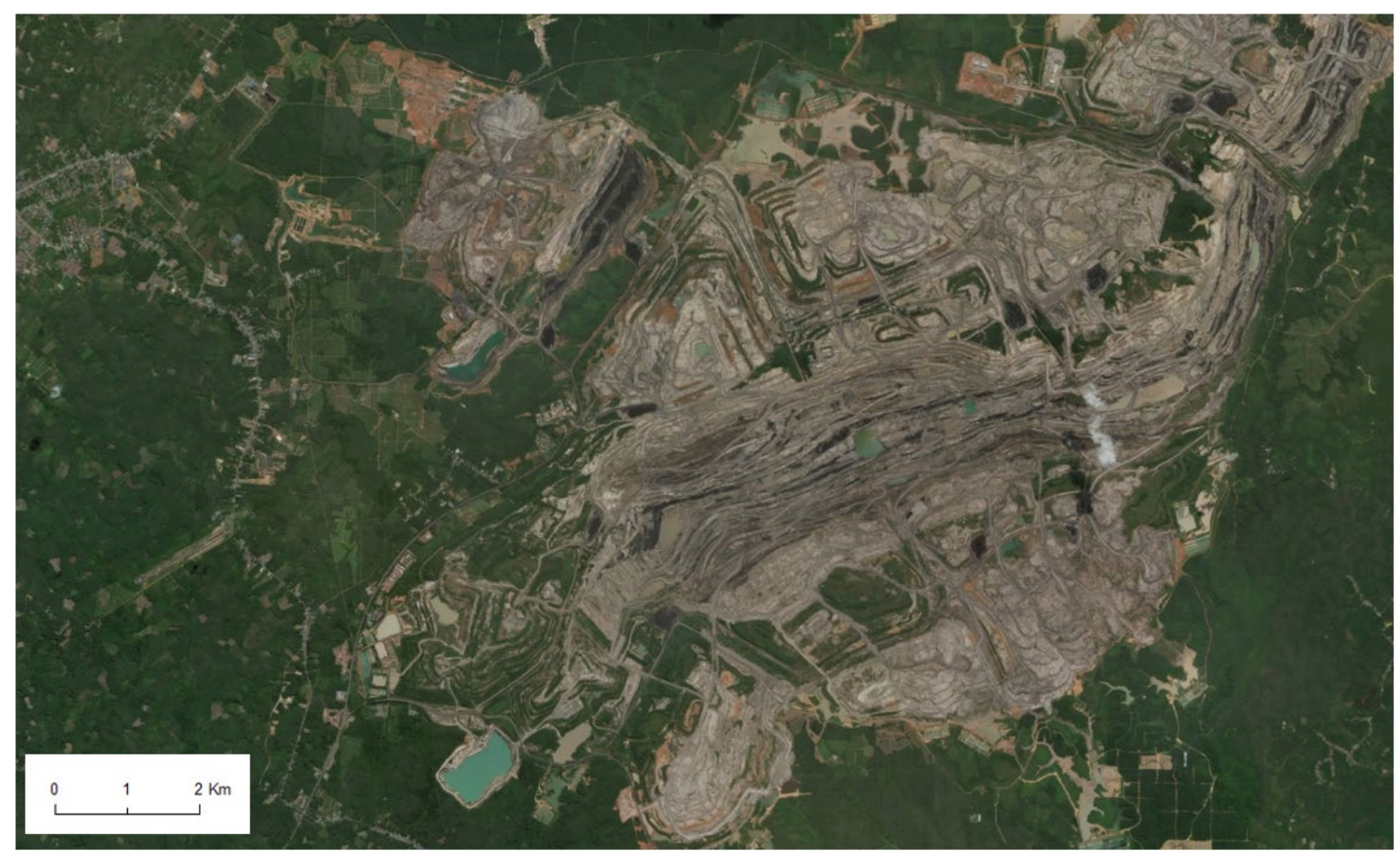

Figure 5 The Adaro complex: coal mines Wara, Tutupan, and Paringin in Indonesia. The risk profile of these mines contains multiple interplay of all ESG risks across the presented framework

\section{Discussion and conclusion}

Our findings provide a sense of the likely risk vulnerability across the coal mining projects, revealing the extent to which closure of these projects will encounter multiple risk factors. A total of 102 mines in the dataset show a high-risk profile with a co-occurrence of seven or eight out of the possible eight ESG risks. 11 projects out of these 102 show an extremely high-risk profile, including all evaluated risks. Recognising the average of 4.2 risks per project, we indicated that most open pit coal mine projects appear to be a subject to a complex interaction of multiple risks across the ESG framework.

Under the scenario of rapid and widespread closure of coal mining projects where nation states reconfigure their resource economies to meet a low carbon future, we confirmed that operating mining companies will face multiple types of concurrent risks in most of the mining regions around the world. Safe and sustainable closure of the projects will require operators to include a range of complex factors to their closure planning and management, particularly where projects are best with multiple medium and high risks. We argue that the presence of multiple risks contributes significantly to the design challenges of closure. Understanding the complexity of ESG risks and their effect on coal mining regions provides an opportunity to re-consider the future of research and innovation in global mining industry.

Considering future mine closure against a broad range of complex factors, we present an ESG risk-based approach that is applicable to any national mining context worldwide. Although this paper does not provide suggestions on how the impacts of the risks can be reduced, the presented framework can contribute to development of adaptive strategies in closure planning by recognizing bounding conditions and risk intensity. Moreover, using global data enable to focus on international difficulties of mine closure, giving a competitive advantage in a global marketplace.

\section{Acknowledgement}

The project is part of a research program called The Mine Life Cycle; one of five strategic research programs at the Sustainable Minerals Institute, The University of Queensland in Australia. 


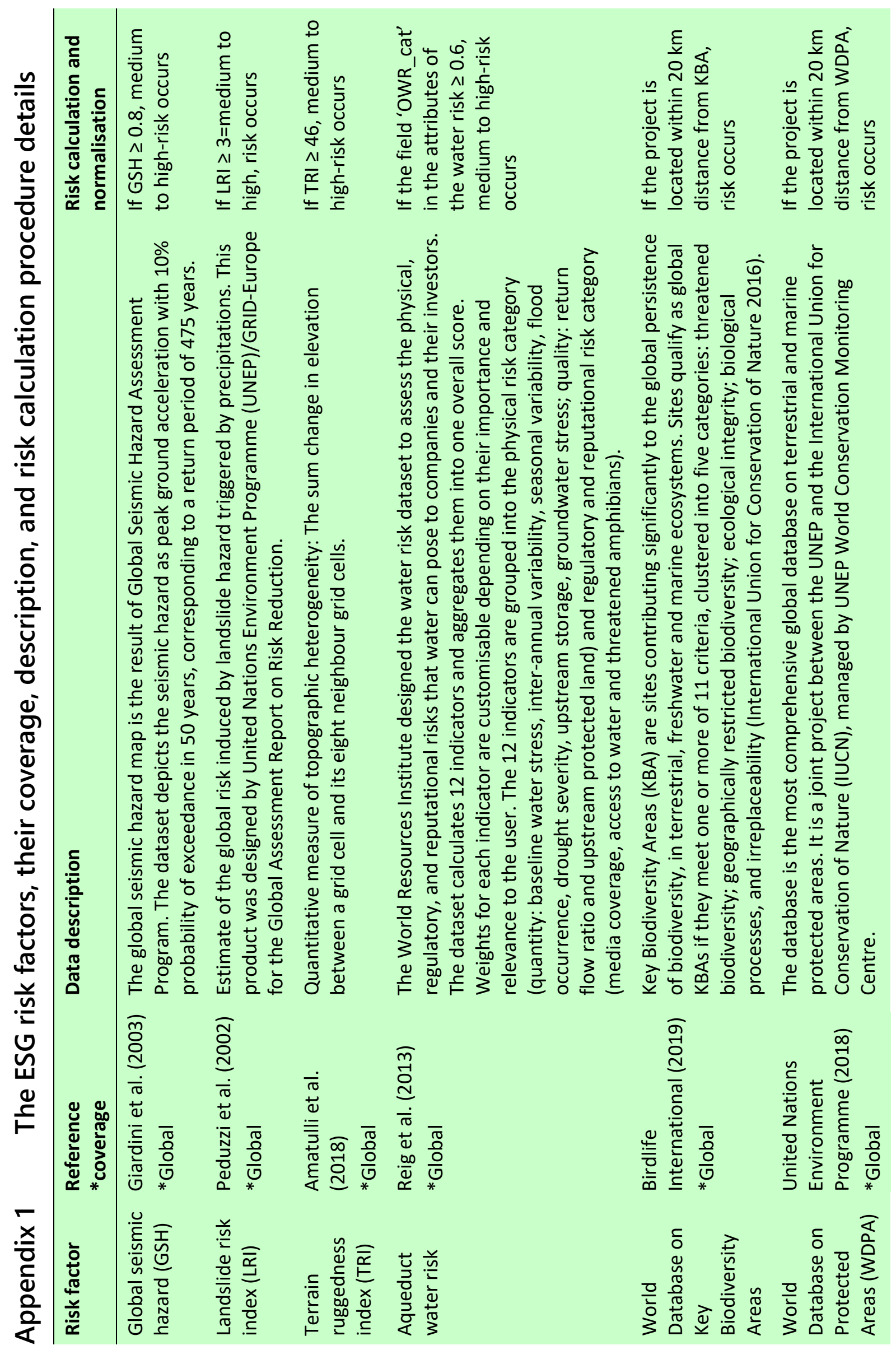




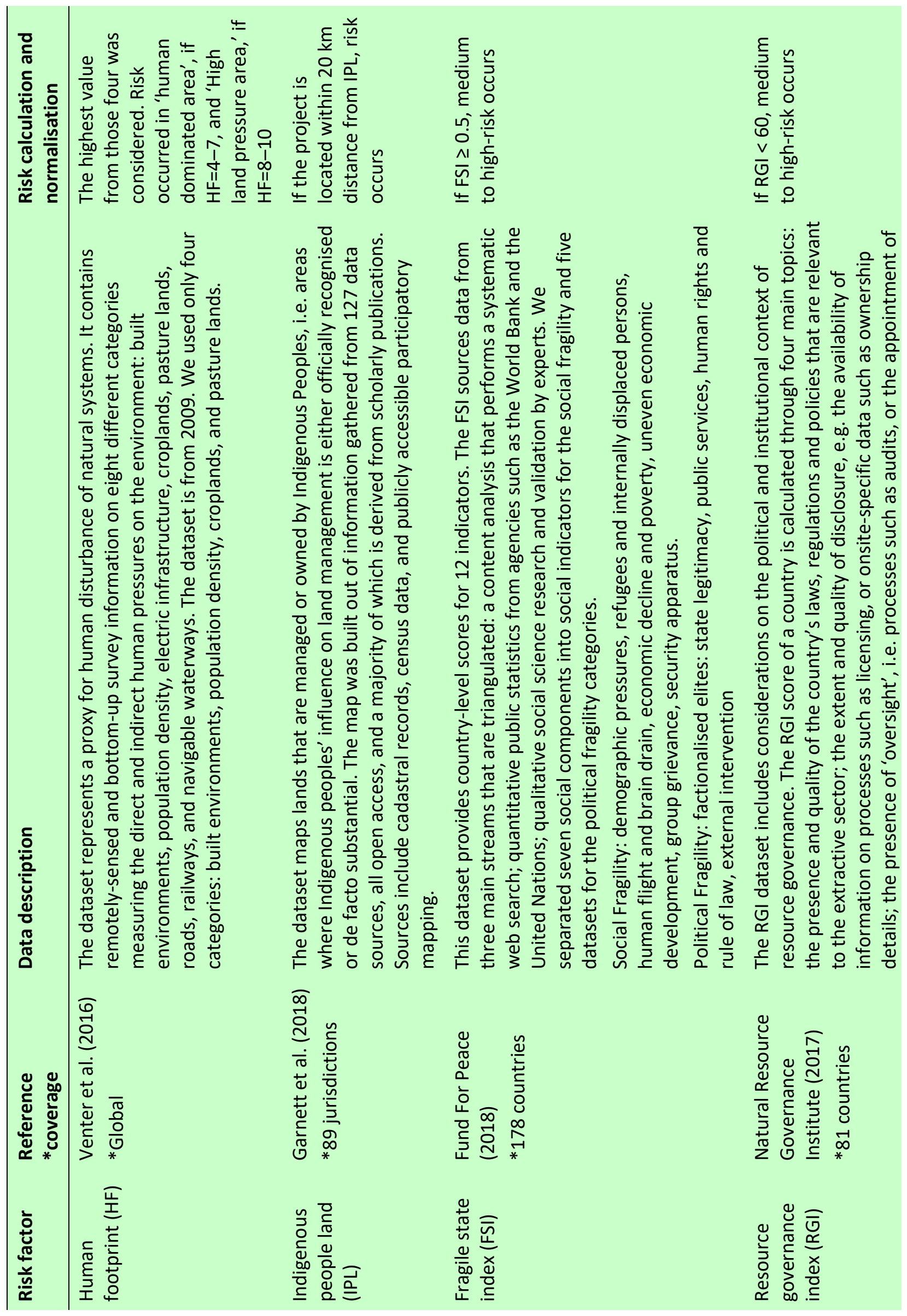




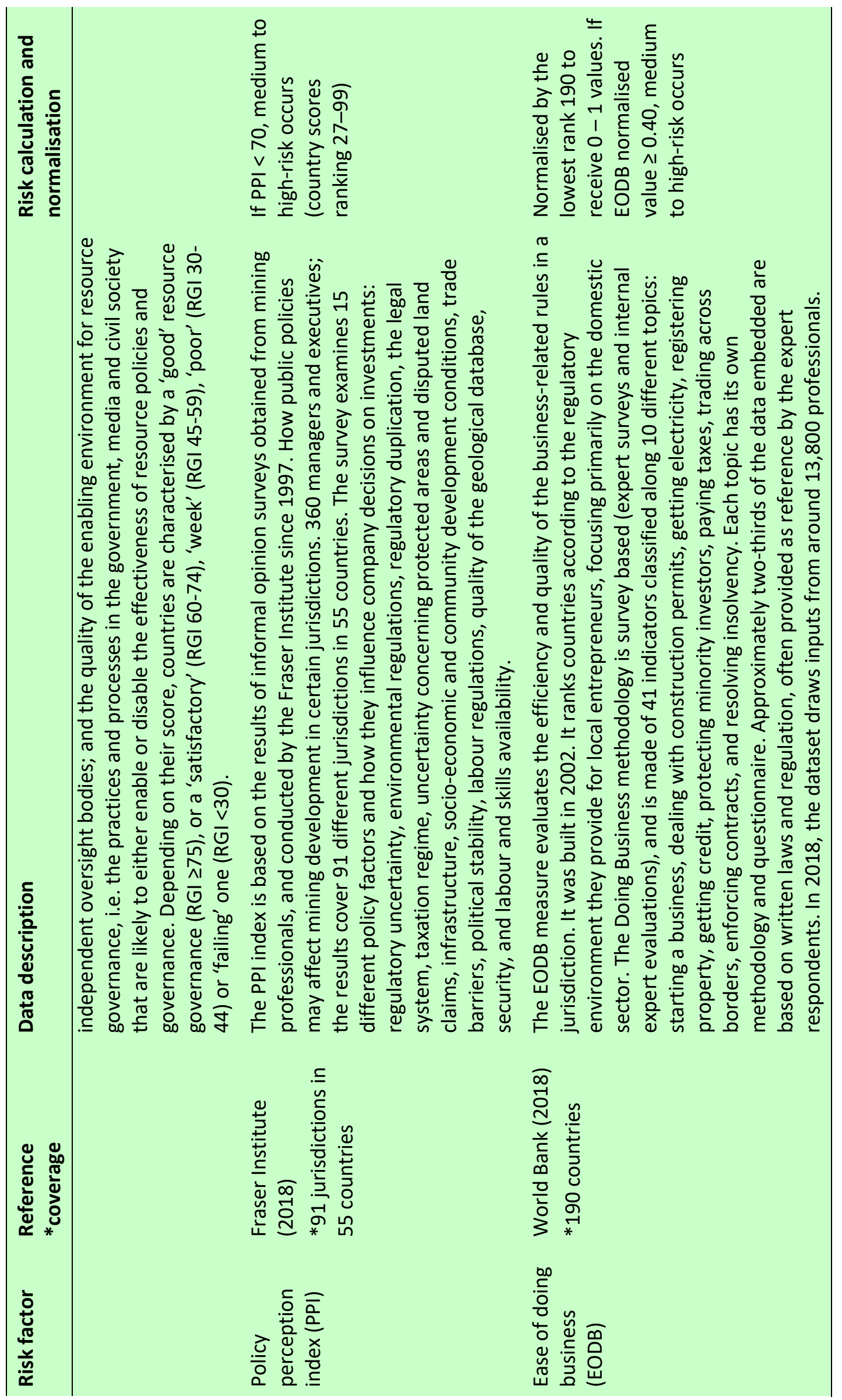




\section{References}

Amatulli, G, Domisch, S, Tuanmu, MN, Parmentier, B, Ranipeta, A, Malczyk, J \& Jetz, W 2018, 'A suite of global, cross-scale topographic variables for environmental and biodiversity modeling', Scientific data, vol. 5, pp.180040.

Bainton, N \& Holcombe, S 2018, 'A critical review of the social aspects of mine closure'. Resources Policy, vol. 59, pp. 468-478.

BirdLife International 2019, What are KBAs \& how are they identified?, viewed 24 March 2019, http://www.keybiodiversityareas.org/what-are-kbas

Buckley, T 2019, Over 100 Global Financial Institutions Are Exiting Coal, With More to Come, Institute for Energy Economics and Financial Analysis, viewed 15 March 2019, http://ieefa.org/wp-content/uploads/2019/02/IEEFA-Report_100-andcounting_Coal-Exit_Feb-2019.pdf

European Environmental Bureau 2019, European parliament calls for EU coal exit by 2030, viewed 4 June 2019, https://meta.eeb.org/2019/03/14/european-parliament-calls-for-eu-coal-exit-by-2030/

Environmental Systems Research Institute 2018, An overview of the Analysis toolbox, viewed 24 March 2019, https://pro.arcgis.com/en/pro-app/tool-reference/analysis/an-overview-of-the-analysis-toolbox.htm

Fraser Institute 2018, Annual Survey of Mining Companies, viewed 24 March 2019, https://www.fraserinstitute.org/studies/annualsurvey-of-mining-companies-2018

Fund for Peace 2018, Fragile State Index, viewed 1 March 2019, https://fragilestatesindex.org/

Garnett, ST, Burgess, ND, Fa, JE, Fernández-Llamazares, Á, Molnár, Z, Robinson, CJ ... \& Collier, NF 2018, 'A spatial overview of the global importance of Indigenous lands for conservation', Nature Sustainability, vol. 1, no. 7, pp. 369.

Giardini, D, Grünthal, G, Shedlock, KM \& Zhang, P 2003, 'The GSHAP Global Seismic Hazard Map', in Lee, W, Kanamori, H, Jennings, P \& Kisslinger, C (eds), International Handbook of Earthquake \& Engineering Seismology, Part A, Volume 81A, Academic Press, Amsterdam, pp. 1233-1239.

Hendrychová, M \& Kabrna, M 2016, 'An analysis of 200-year-long changes in a landscape affected by large-scale surface coal mining: History, present and future', Applied geography, vol. 74, pp.151-159.

International Union for Conservation of Nature 2016, A Global Standard for the Identification of Key Biodiversity Areas: version 1.0, Gland, Cambridge, viewed 24 March 2019, https://portals.iucn.org/library/node/46259

Lechner, AM, McIntyre, N, Witt, K, Raymond, CM, Arnold, S, Scott, M \& Rifkin, W 2017, 'Challenges of integrated modelling in mining regions to address social, environmental and economic impacts', Environmental modelling \& software, vol. 93, pp.268-281.

McGowan, M \& Cox, L 2019, 'Court rules out Hunter Valley coalmine on climate change grounds', The Guardian, viewed 4 June 2019, https://www.theguardian.com/australia-news/2019/feb/08/court-rules-out-hunter-valley-coalmine-climate-changerocky-hill

Natural Resource Governance Institute 2017, 2017 Resource Governance Index, viewed 24 March 2019, https://resourcegovernance.org/sites/default/files/documents/2017-resource-governance-index.pdf

Organisation for Economic Co-operation and Development 2017, Investment governance and the integration of environmental, social and governance factors, https://www.oecd.org/finance/Investment-Governance-Integration-ESG-Factors.pdf

O'Faircheallaigh, C 2017, 'Shaping projects, shaping impacts: community-controlled impact assessments and negotiated agreements', Third World Q, vol. 38, no. 5, pp. 1181-1197.

Peduzzi, P, Dao, H, Herold, C \& Mouton, F 2002, Global Risk and Vulnerability Index Trends Per Year (Gravity) Phase li: Development, Analysis And Results, viewed 24 March 2019, https://wedocs.unep.org/handle/20.500.11822/8819

Ranängen, H \& Lindman, Å 2017, 'A path towards sustainability for the Nordic mining industry', Journal of Cleaner Production, vol. 151, pp.43-52.

Reig, P, Shiao, T \& Gassert, F 2013, Aqueduct Water Risk Framework, World Resources Institute, Washington, viewed 20 March 2019, http://pdf.wri.org/aqueduct_water_risk_framework.pdf

S\&P 2019, S\&P Global Market Intelligence. Thomson Reuters, New York, viewed 24 March 2019, https://www.spglobal.com/marketintelligence/en/

Salmon, DA 2018, 'Managing uncertainty in planning opencast coal final void closure and relinquishment' in Wolkersdorfer, C, Sartz, L, Weber, A, Burgess, J \& Tremblay, G (eds), Proceedings of the 11th International Conference on Acid Rock Drainage, International Mine Water Association, Wendelstein, pp 64-69.

United Nations Development Programme 2015, Transforming our World: the 2030 Agenda for Sustainable Development, New York.

United Nations Environment Programme 2018, World Database on Protected Areas, viewed 24 March 2019, https://www.iucn.org/theme/protected-areas/our-work/world-database-protected-areas

Valenta, RK, Kemp, D, Owen, JR, Corder, GD, \& Lèbre, É 2019, 'Re-thinking complex orebodies: Consequences for the future world supply of copper', Journal of Cleaner Production, vol. 220, pp. 816-826.

Venter, O, Sanderson, EW, Magrach, A, Allan, JR, Beher, J, Jones, KR ... \& Levy, MA 2016, 'Sixteen years of change in the global terrestrial human footprint and implications for biodiversity conservation', Nature Communications, vol. 7, pp. 12558.

Walters, A 2016, The Hole Truth: To Mess Coal Companies Plan to Leave in NSW, Energy Resource Insights, viewed 24 March 2019 , http://downloads.erinsights.com/reports/the_hole_truth_LR.pdf

Wood Mackenzie 2018, Adaro Wara Coal Mine, Wood Mackenzie, Edinburgh.

World Bank 2018, Rankings \& Ease of Doing Business Score, viewed 24 March 2019, http://www.doingbusiness.org/en/rankings 